\title{
Particle Physics: CP Violation in Hyperon Decays
}

\author{
University of Michigan DE-FG02-96ER40999 Final Report \\ Grant Period: 11/1/97-10/31/99 Remaining Funds \$0 \\ Project Director: Michael J. Longo
}

The primary research activities under this grant were in E871 (HyperCP) at Fermilab, a search for $C P$ violation in hyperon decays which completed data taking in January, 2000. Hyper $C P$ is an experiment designed to perform a sensitive search for direct $C P$ violation in the decays of cascade $(\Xi)$ and $\Lambda$ hyperons by looking for an asymmetry between particle and antiparticle decay parameters. The experiment is expected to achieve a sensitivity $\approx 10^{-4}$ in the decay parameters. Standard model predictions for this $C P$-violating asymmetry range from 0.3 to $5 \mathrm{x}$ $10^{-4}$. A difference between the decay parameters for particle and antiparticle is direct evidence that $C P$ symmetry is violated. A non-zero asymmetry would be the first evidence for $C P$ violation outside of the $\mathrm{K}^{0}$ system. Recent results from $\mathrm{KTeV}$ indicate a direct $C P$ violation in $\mathrm{K}^{0}$ decays, which suggests that $C P$ violation will appear in other decays.

In addition, we will look at a number of rare hyperon decays involving muons. These probe important new physics topics such as Majorana neutrinos and lepton number violating processes. The latter are of great current interest because new evidence for neutrino oscillations indicate lepton flavor violation does occur. Our data will lead to an improvement in the limits on branching ratios for these processes typically by three to four orders-of-magnitude. The muon detector construction and data resulting from it have been the responsibility of the Michigan group. We are now leading the analysis of the rare muon-related decay modes, and were responsible for the muon system and beam monitor upgrades for the 1999 run.

The 1999 run began in June, 1999 and continued into January, 2000. We collected over twice as much data as we did in the 1997 run. The total data sample required approximately 30,000 Exabyte tapes. The data analysis is expected to continue for several years.

Our group currently consists of Principal Investigators M. J. Longo and H.R. Gustafson; postdoctoral scholar H. Park; and graduate student Alex Lehmann. H. Park is located at Fermilab and is working full-time on E871 analysis. Former graduate student Kael Hanson finished his thesis and took a postdoc position at the University of Pennsylvania.

\section{Muon System and Beam Monitor Upgrades for 1999 Run}

The Michigan group was responsible for the entire muon systems and, in addition, a neivi beam monitor that was installed for the $1999 \mathrm{run}$. The beam monitor consists of two scintikEtor hodoscope planes, one horizontal and one vertical with a total of 24 counters. This was designed by MJ, constructed mostly by an undergraduate, Josh Simon, and installed and tested by $\mathrm{H}$. Park, HRG, and Alex Lehmann. This system has worked well.

A number of muon system upgrades were accomplished. These include:

- Separating horizontal and vertical muon hodoscope planes to decrease muon trigger

- Installation of additional steel ahead of west side muon detector to reduce rates.

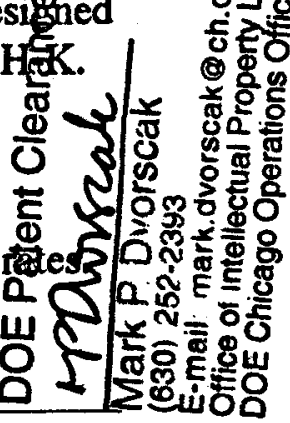




\section{DISCLAIMER}

This report was prepared as an account of work sponsored by an agency of the United States Governmeat. Neithet the United States Governmeat nor any agency thereof, nor any of their employees, makes any warranty, express or implied, of assumes any $\mathrm{kg}$ al liability or responsibility for the aceuracy, completedess, or usefulness of any information, apparatus, product, or process disclosed, or represents that its use would not infringe privately owned rights. Reference berein to any specific commereial product, process, or service by trade name. trademark, manufaetures, or otherwise does not necessarily constitute or imply its eadorsement, recommendation, or favoring by the United States Governmeat or any agency thereof. The riews and opinions of authors expréssed herein do not pecessarily state or reflect those of the United States Governmeat or any ageacy thereof. 


\section{DISCLAIMER}

Portions of this document may be illegible in electronic image products. Images are produced from the best available original document. 
- Changeover to "fast gas" for muon chambers (Ar-CH4-CF4)

- Changeover to "standard" readout electronics for muon system ( the previous FEM electronics was no longer supported by Academia Sinica). ing.

These upgrades went well, but the work and debugging turned out to be quite time-consum-

TABLE 1. Summary of E-871 Runs

Total Analysis Quality Tapes Vaulted $=9,376$

Data Volume 40 TB

Anti-Cascade Triggers on Tape: 24.5 Billion

Cascade Triggers on Tape: 15 Billion

Total Triggers on Tape: 63 Billion

1999

Total Analysis Quality Tapes Vaulted $=18,838$

Data Volume $\sim 71$ TB

Anti-Cascade Triggers on Tape: 57 Billion

Cascade Triggers on Tape: 25 Billion

Total Triggers on Tape: 153 Billion 